\title{
Al-Generated Inventions and IPR Policy During the COVID-19 Pandemic
}

\section{凡目 Chhavi Sharma}

Research Officer, Indian Institute of Public Administration, PhD. Address: Indraprastha Estate, Ring Road, New Delhi 110002, India. E-mail: chhavi.mail@gmail.com.

\section{目 Reeta Sony}

Assistant Professor, Centre for Studies in Science Policy, School of Social Sciences, Jawaharlal Nehru University, PhD. Address: New Mehrauli Road, JNU Ring Rd, New Delhi 110067, India. E-mail: reetasony@msil.jnu.ac.in

«Actions are right in proportion as they tend to promote happiness; wrong as they tend to produce the reverse of happiness. By happiness is intended pleasure and the absence of pain».

John Stuart Mill

\section{目目 Abstract}

According to the World Health Organisation's (WHO) official website for coronavirus, the disease has spread to approximately 214 countries and regions. While the disease is spreading mercilessly around the world, science and technology are giving it an equal fight. The pandemic is a test of governments' medical capacity and their political will; it also raises several philosophical questions. It is a test of humans as a unit. A test of humanity as a whole. Artificial Intelligence (Al) is intended to imitate human cognitive functions. It will bring significant change to health care, driven by the growing accessibility of healthcare data and rapid advancement of analytics practices. During the current COVID-19 pandemic, Al is being used to assist and advise doctors in establishing a diagnosis, to support radiologists in refining image explanation, and help in the advancement of drug discovery research. The upsurge of new technologies gives rise to new questions. There is still considerable uncertainty in the field of Intellectual Property (IP) protection of Al-generated works. Al does not have legal personhood, so the question remains about whether it holds any IP rights. In this article, we discuss the IP rights of Al-generated works with respect to the COVID-19 pandemic. The objective of this study is to determine the impact of international and national laws and treaties on IP rights for Al-generated solutions to the pandemic, as well as to study an alternative temporary mechanism to make IP widely available to mobilise resources and manufacture critical products to prevent, diagnose or treat COVID-19. The paper attempts to strike a balance between the needs of health care, life-threatening emergencies and IP rights by applying a utilitarian theory of IP law that denotes the «utility» of all people, aiming to secure «the greatest good for the greatest number». 


\section{O-A 国 Keywords}

Pandemic, COVID-19, Al-generated Work, Intellectual Property, Data Protection, Privacy, Health Care, Crisis, Patent Pool, Open Access, Cooperation, Harmony.

For citation: Sharma C., Sony R. Al-Generated Inventions and IPR Policy during the COVID-19 Pandemic // Legal Issues in the Digital Age, no 2, pp. 63-91.

DOI: $10.17323 / 2713-2749.2020 .2 .63 .91$

\section{Introduction}

Ever since the first case of coronavirus ${ }^{1}$ (COVID-19) ${ }^{2}$ occurred in Wuhan, China, it has spread to about 216 other regions and countries. As various countries initiated their response to the virus, they leaned heavily on the technology sector and specifically on artificial intelligence (AI), data science, and technology to track and fight the pandemic. Tech start-ups are intrinsically involved with academics, clinicians and government entities around the world in order to stimulate technology as the virus continues to spread.

Technology and medical companies around the world are intensifying their efforts to tackle the effects of the COVID-19 pandemic. Life-saving treatments for the disease are being developed using Artificial Intelligence (AI) and supercomputers. The COVID-19 High Performance Computing Consortium ${ }^{3}$, introduced in late March by the White House ${ }^{4}$, aims to bring together industry leaders in AI, national laboratories and academics to "significantly advance the

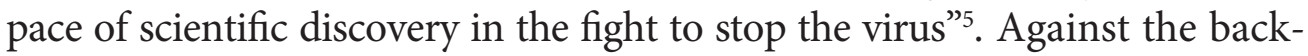

${ }^{1}$ Corona viruses are a large family of viruses which may cause illness in animals or humans. In humans, several coronaviruses are known to cause respiratory infections ranging from the common cold to more severe diseases such as Middle East Respiratory Syndrome (MERS) and Severe Acute Respiratory Syndrome (SARS).

2 The most recently discovered coronavirus causes coronavirus disease COVID-19.

3 The COVID-19 High Performance Computing (HPC) Consortium is a unique private-public effort spearheaded by the White House Office of Science and Technology Policy, the U.S. Department of Energy and IBM to bring together federal government, industry, and academic leaders who are volunteering free compute time and resources on their world-class machines

${ }^{4}$ White House Announces New Partnership to Unleash U.S. Supercomputing Resources to Fight COVID-19. Available at: https://www.whitehouse.gov/briefings-statements/white-houseannounces-new-partnership-unleash-u-s-supercomputing-resources-fight-covid-19/ (accessed: 23.05.2020)

${ }_{5}^{5}$ Marr B. Coronavirus: How Artificial Intelligence, Data Science and Technology is Used to Fight the Pandemic. Available at: https://www.forbes.com/sites/bernardmarr/2020/03/13/coronavirus-how-artificial-intelligence-data-science-and-technology-is-used-to-fight-the-pandemic/ \#6f966c0e5f5f.) (accessed: 23.03.2020) 
drop of COVID-19, industries are looking to AI for predictive modelling, tracking, diagnosis and prognosis. While the use of AI will unquestionably result in credible invention, data, test results, and any inventions resulting from its use will raise questions about how to best protect these innovations and who should receive credit as an inventor.

\section{Science, Technological Inventions and Pandemics}

\section{Technologies in earlier pandemics}

"A pandemic is the worldwide spread of a new disease. An influenza pandemic occurs when a new influenza virus emerges and spreads around the world, and most people do not have immunity"6. The world has seen several pandemics in the past, which are indicated in the table below. The development of science and technology and their application to health care was rare in earlier times.

Table 1. Global pandemics

\begin{tabular}{|l|}
\hline The Plague of Justinian \\
\hline Black death \\
\hline Smallpox (15th-17th centuries) \\
\hline Cholera (1817-1823) \\
\hline Spanish Flu or H1N1 (1918-1919) \\
\hline Hong Kong Flu or H3N2 (1968-1970) \\
\hline HIV/AIDS (1981 - present) \\
\hline SARS (2002-2003) \\
\hline Swine Flu or H1N1 (2009-2010) \\
\hline Ebola (2014-2016) \\
\hline Coronavirus, or COVID-19 (2019- present) \\
\hline
\end{tabular}

In contrast, with today's pandemic, COVID-19, the genome was sequenced within a short span of time after the disease spread in the Chinese city of Wuhan. Scientists in China demonstrated that it was a totally new virus, despite being closely related to the coronavirus $(\mathrm{CoV})$ that led to severe acute respiratory syndrome (SARS).

${ }^{6}$ What is a pandemic? Available at: https://www.who.int/csr/disease/swineflu/frequently_ asked_questions/pandemic/en/ (accessed: 23.03.2020) 


\section{Pandemics in India}

Prior to the COVID-19 pandemic, India has encountered numerous pandemics and epidemics like influenza, cholera, dengue, smallpox and others throughout history. While some could be eradicated, others posed a public threat. Some of the persistent causes of these pandemics were lack of sanitation, incompetent health care, and malnutrition. While vector-borne outbreaks attributed to the tropical climate and seasonal rains ${ }^{7}$. The two primary pandemics in Indian history were the recurrent cholera outbreaks in the 19th century and the Spanish flu of 1918.

In the 19th century, six major cholera pandemics broke out in 1819 to 1899. The first pandemic in 1817 was probably the most terrifying when the first case was witnessed on August 23. The worst affected people were the poor and slum- dwellers.

Influenza, caused by the H1N1 strain of influenza and also known as the «Spanish Flu of 1918-1919”, caused approximately 20-50 million deaths worldwide. The disease spread globally, and India was assumed to be the epicentre. Crucial factors leading to the brutality and spread of the flu were the higher virulence and rapidity of the virus strain along with the humidity caused by monsoons. It spread quickly in India and distressed the economy. Social distancing was the only well recognised way to reduce the effects of earlier pandemics.

During all of these earlier pandemics, India had been following the British patenting system where IPR laws were stringent which led to a stringent patenting regime. Product patents were challenging to acquire. Furthermore, India practised a traditional or alternative medicine system.

\section{COVID-19}

COVID-19 is a communicable disease caused by a recently discovered coronavirus that originates from a virus family that also causes Severe Acute Respiratory Syndrome (SARS) and the common cold. COVID-19 virus infection in most people causes mild to moderate respiratory illness.

Common symptoms of the disease include:

Fever

Dry cough

Fatigue

Mehta K. What we can learn from earlier pandemics in the history of India. Available at: https://www.timesnownews.com/india/article/what-we-can-learn-from-earlier-pandemics-in-thehistory-of-india/574255 (accessed: 23.03.2020) 
Less common symptoms are:

Aches and pains

Sore throat

Diarrhoea

Conjunctivitis

Headache

Loss of taste or smell

Rash on skin

Discolouration of fingers or toes

Less prevalent serious symptoms include:

Difficulty breathing

Shortness of breath

Chest pain or pressure

Loss of speech

Loss of movement [Wu Y. et al, 2020: 217-220; Huang C. et al, 2019]

\section{Role of data-centric technologies in pandemics}

Data will remain significant for thousands of years. It was as important many years ago as it is today. Data collection methods and techniques continue to improve. Each day we open our eyes, and we are flooded with information about the world around us, which gives us the perspective we need to keep moving. This process of collecting data about the world around us gives us an idea about how to get what we want. In a similar manner datadriven technology help us obtain data and help to put it into a perspective we can apply in order to envision a clear path from Point A to Point B.

Although data-driven decision making has existed for many years, several new technologies are coming out of the woodwork that have begun changing the game.

Data-driven technologies are crucial in pandemic responses. Population and individual data advance the investigation and identifications of disease, understandings and testing of treatments, and execution of public health measures. The Covid-19 pandemic has established a host of data-intensive initiatives, projects and schemes, which often involve pioneering uses of existing datasets, supported by rapid advances in technologies, including machine learning, and enabled through data sharing across organisations and countries, exploiting the global nature of the pandemic, an increase in public-private partnerships and worldwide collaborations. 
The imperative to ensure access to data is clear but not straightforward as demonstrated by controversies relating to contact tracing apps and proposed $^{8}$ immunity passports'. Such technologies are often developed rapidly, in conjunction with commercial organisations and with little opportunity for public deliberation over whether such uses are acceptable. Such data uses raise various important regulatory concerns, including ethical, legal and social implications for such things as privacy, trust, transparency and equality. These can have immediate and long-lasting consequences for both individuals and populations. Some of the recent data-driven technologies are based on big data, business intelligence, analytics and artificial intelligence.

\section{Artificial intelligence (AI)}

Artificial Intelligence denotes computer systems that are proficient in executing tasks such as speech recognition, visual perception, decisionmaking and translation that otherwise would require human intelligence. Weak AI systems are incapable of thinking for themselves but can revert to explicit situations. Robust AI systems are being developed in a way that involves learning from prior practices and while reasoning and performing like humans ${ }^{10}$.

AI is developing so rapidly that related legal regulation is falling behind. This radical technology causing radical innovations ${ }^{11}$ will be incorporated in nearly every area of life, and the need for legal guidance on this topic is increasing significantly, particularly as it relates to intellectual property law. Developers and inventors have gained the capacity to create machine learning technologies that can autonomously generate inventions. A new issue of inventorship has appeared, with the question being: Do computers have the

${ }^{8}$ Edmond C. What is an immunity passport and could it work? Available at: https://www. weforum.org/agenda/2020/06/immunity-passport-quarantine-work-covid-19/ (accessed: 11.07.2020)

9 Among the measures being considered by governments, including Chile, Germany, Italy, Britain and the US, are immunity passports - a form of documentation given to those who have recovered from COVID-19.

${ }^{10}$ White House Announces New Partnership...

${ }^{11}$ Occasionally a technology dislocates established framework events; the technology has the capacity to redesign and refine the space and the boundary. This is a radical technology that causes radical innovations. 
ability to be inventors? If not, who can claim the rights to inventions that result from $\mathrm{AI}$ inventors?

\section{Al is a data-centric technology}

The open-source community ${ }^{12}$ has been the chief technology driver behind the big data push. It is a group of individuals who (often voluntarily) work together to develop, test of modify open source software products. It has provided the skills for an added data-centric approach, which is the ability to generate a working model that might predict future inferences grounded in previous actions. Adding original data improves the process. Big data signifies the volume of data that is being made daily and the speed (velocity) at which that data is generated; it also signifies diverse sorts of data formats, such as structured or unstructured, with a distinction in data quality.

AI builds on top of HPC for large-scale computer processing and on big data with the support of the open-source community. Data is the real IP and the key distinguishing factor between competitors. The algorithms used in AI are software frameworks that are formed and collectively shared by many people. The allocation of notions and perceptions is a key component of the growing success of AI.

With the democratisation of data comes the possibility for non-data scientists to gather and analyse data with little assistance and without the need for a science degree. There are abundant guides and tutorials that can be used as an introduction to working with AI. Today, the data central to AI is mostly trivial, but in the future, the data used will define triumph or disaster.

\section{How Al is helping in the fight against COVID-19?}

The Centre for Disease Control and Prevention (CDC) and the World Health Organization (WHO) have implemented analytics and big data in their attempts to review pandemics and to find a lasting solution. AI is being used as a tool in the fight against the viral pandemic. The press and the scientific community are highly anticipating that data science and AI can be used to counter the coronavirus. Michael Kratsios, the US chief technology officer, said, «with data scientists and machine language experts mining the literature compilation known as COVID-19 Open Research Dataset, experts

\footnotetext{
${ }_{12}$ A group of individuals who (often voluntarily) work together to develop, test, or modify open source software products.
} 
and White House officials expect to get help developing vaccines, forming new guidelines on how long social distancing should be maintained and other insights.» In a time of crisis, Chinese tech companies such as Alibaba and Baidu are offering free AI technologies and computing capabilities in order to aid public research institutions and buy time to combat the coronavirus. AI has also helped on the frontline. Chatbots lessen the pressure on hospital and government personnel by robotically answering queries from members of the public, and even counselling individuals about whether they need to undergo screening in hospital or stay at home for a 14-day quarantine. In the face of an abrupt attack from COVID-19, China's ability to adjust and fight back with AI is an indication that the country's investments in AI and related technologies are paying off. This is the first time that AI has been used so extensively to combat a pandemic. Without $\mathrm{AI}^{13}$, the spread of the novel coronavirus [Cutillo C. et al, 2020: 1-5] would have been much quicker and more damaging ${ }^{14}$. Table 2 below provides detailed description of various companies and their efforts to combat COVID-19.

The COVID-19 detection neural network (COVNet), a deep learning model, was developed to extract visual features from Computed Tomography (CT) exams to detect and diagnose the presence of the COVID-19 virus ${ }^{15}$, $16,17,18,19,20$ [Li L. et al, 2019]. As the world races to find a cure for Covid-19, a Mumbai-based data scientist and his team have discovered three molecular

${ }^{13}$ Ratnam G. Government Technology. Available at : https://www.govtech.com/products/CanAI-Fill-in-the-Blanks-About-Coronavirus-Experts-Think-So.html (accessed: 25.03.2020)

${ }^{14}$ Senior A. et al. Deep Mind. Available at: https://deepmind.com/blog/article/AlphaFoldUsing-AI-for-scientific-discovery (accessed: 25.03.2020)

${ }^{15}$ Chun A. Available at: https://www.scmp.com/comment/opinion/article/3075553/timecoronavirus-chinas-investment-ai-paying-big-way?fbclid= t2aasnXM9VgOSSZMYCtSfb2eGZDinOOpSWyJeVo. (accessed: 25.03.2020)

${ }^{16}$ Sagar R. 11 Ways AI is helping fight Coronavirus. Available at : https://analyticsindiamag. com/ai-corona-covid19-fight-deepmind-alibaba-baidu-algorithm/ (accessed: 01.06.2020)

17 Yakobovitch D. Medium. How to fight the Coronavirus with AI and Data Science. Available at: https://towardsdatascience.com/how-to-fight-the-coronavirus-with-ai-and-data-scienceb3b701f8a08a (accessed: 01.06.2020)

${ }_{18}$ Imaging Technology News. Researchers use AI to detect Covid -19. Available at : https://www. itnonline.com/content/researchers-use-ai-detect-covid-19 (accessed: 01.06.2020)

19 Johnson A. How Artificial Intelligence is aiding the fight against Coronavirus. Available at: https://www.datainnovation.org/2020/03/how-artificial-intelligence-is-aiding-the-fightagainst-coronavirus (accessed: 01.06.2020)

${ }^{20}$ Scedullari M. Five Companies Using AI to fight Coronavirus. Available at : https://spectrum. ieee.org/the-human-os/artificial-intelligence/medical-ai/companies-ai-coronavirus (accessed: 01.06.2020) 
compounds with the help of AI; it is claimed that these compounds can be synthesised and tested more in order to find a novel drug to fight Covid-19.

Table 2. Description of various companies and their efforts to combat COVID-19

\begin{tabular}{|c|c|}
\hline Organisation & Attempt/ Solution to combat Covid-19 \\
\hline DeepMind & $\begin{array}{l}\text { AlphaFoldSystem - used to predict the protein structure that may help } \\
\text { in research }\end{array}$ \\
\hline AliBaba & $\begin{array}{l}\text { The organisation claims that its new AI system can detect coronavirus } \\
\text { in CT scans of patients' chests with } 96 \% \text { accuracy in a record time } \\
\text { of about } 20 \text { seconds. }\end{array}$ \\
\hline Baidu research & $\begin{array}{l}\text { Their team has released a tool - LinearFold - which has the ability } \\
\text { to reduce } 2019-\mathrm{nCoV} \text { prediction time to } 27 \text { seconds from } 55 \text { seconds. } \\
\text { This may help reduce prediction time for the virus and accelerate drug } \\
\text { discovery. }\end{array}$ \\
\hline $\begin{array}{l}\text { Harvard Medical } \\
\text { School }\end{array}$ & $\begin{array}{l}\text { John Brownstein of Harvard Medical School is associated with } \\
\text { an International team that is deploying machine learning to skim } \\
\text { through social media data from official public health channels and data } \\
\text { from healthcare providers in order to prepare real-time health analytics } \\
\text { of the outbreak. }\end{array}$ \\
\hline $\begin{array}{l}\text { BlueDot } \\
\text { Surveillance }\end{array}$ & $\begin{array}{l}\text { This organisation has also contributed by collecting disease data from } \\
\text { various online sources, and hence deploying airline flight information } \\
\text { in order to generate predictions about where infectious diseases may } \\
\text { appear next; air routes are a common disease vector. }\end{array}$ \\
\hline Insilico & $\begin{array}{l}\text { Insilico Medicine is using Generative Adversarial Networks (GANs) } \\
\text { to filter molecule designs. }\end{array}$ \\
\hline inferVision & $\begin{array}{l}\text { Doctors in China have been using a tool to assist them in quickly } \\
\text { diagnosing potential coronavirus patients. This AI-based software } \\
\text { is called inferVISION, and can quickly highlight potential troubling } \\
\text { cases in record time. } \\
\text { It deploys NVIDIA's Clara SDKs, which is NVIDIA's AI healthcare } \\
\text { application framework for AI-powered Medical Imaging. }\end{array}$ \\
\hline BenevolentAI & $\begin{array}{l}\text { With the aid of BenevolentAI's software, researchers have identified } \\
\text { a possible drug called 'Baricitinib'. }\end{array}$ \\
\hline SenseTime & $\begin{array}{l}\text { Application of AI to scan faces of people with masks. Contactless } \\
\text { identification of patients using their temperature detection software } \\
\text { in parts of Beijing, Shanghai and Shenzhen }\end{array}$ \\
\hline $\begin{array}{l}\text { Pudu Technology, } \\
\text { Micro- } \\
\text { MultiCopter }\end{array}$ & $\begin{array}{l}\text { The companies' drones are deployed to monitor the outbreak in various } \\
\text { parts of China }\end{array}$ \\
\hline UVD Robots & Using robots to disinfect patient rooms with zero human interference \\
\hline
\end{tabular}




\section{CORD-19 dataset description}

In response to the COVID-19 pandemic, the White House and an alliance of leading research groups have prepared the COVID-19 Open Research Dataset (CORD-19). CORD-1921 is a dataset of 134,000 scholarly articles about COVID-19, SARS-CoV-2, and related coronaviruses; 60,000 of the articles have full text. This dataset is freely available to the global research community. Recent advances in natural language processing and other AI techniques can be applied to the dataset as a way of generating new perspectives to support the continuing fight against this infectious disease. There is increasing urgency for these tactics given the rapid development of the novel coronavirus literature, which makes it difficult for the medical research community to keep up.

\section{Applications of Al to COVID-19}

The applications may be categorised as follows:

Detecting and diagnosing infections

Monitoring treatment

Tracing contact of individuals

Predicting cases and fatality

Assistance in developing drugs and vaccines

Reducing the workload of healthcare workers

Preventing disease occurrence

Artificial intelligence is a tool that can benefit in its ability to recognise early coronavirus infections and also help with intensive care of infected patients. It can advance stable treatment and decision making by developing useful algorithms. AI helps treat patients infected with COVID-19 and ensures proper health monitoring for them. It can trace the COVID-19 crisis at diverse levels, such as through molecular, medical and epidemiological applications. It also helps ease research on this virus by analysing available data. AI can support the development of proper treatment regimens, inhibition strategies, as well as drugs and vaccines.

The drawbacks of using the technology are simply legal and intellectual property rights issues with AI.

${ }^{21}$ COVID-19 Open Research Data Challenge (CORD-19). Available at: https://www.kaggle. com/allen-institute-for-ai/CORD-19-research-challenge (accessed: 01.06.2020) 


\section{Intellectual property}

Intellectual property (IP) ${ }^{22}$ are the creations of the mind, such as inventions; literary and artistic works; designs; and symbols, names and images used in commerce. IP is protected in law by, for example, patents, copyright and trademarks, which enable people to earn recognition or financial benefit from what they invent or create. By striking the correct balance amid the benefits of innovators and the wider public interest, the IP system aims to create an environment in which originality and novelty can flourish.

\section{Al-generated works ${ }^{23}$ and IPR}

\section{Owners of Al-generated work}

To answer the question about the ownership of AI-generated works, we need to know who is the author of a work is. The author is the person who creates the work. The creation of a work is essentially a human activity.

In most countries' jurisdictions, if no human author can be identified for a work, no copyright will exist, and hence it will fall into the public domain. There may be copyright in an AI algorithm itself; for example, computer programs are protected by copyright, which are separate works whose authorship (and ownership) is different from the work it creates ${ }^{24}$.

In the UK, lawmakers in Parliament wanting to encourage investment in AI in the 1980s formed a category of "computer-generated works» in section 9(3) of the Copyright Designs and Patents Act 1988 (CDPA). These are works that are generated by a computer with no human author. The author is therefore considered to be the person «by whom the arrangements necessary for the creation of the work are undertaken.»

Overlaps between AI and IP can be discussed as:

$\mathrm{AI}$ as a technology that may contribute to managing IP rights

IP as a regime for the shield of AI

IP as an obstacle to the transparency of AI systems

${ }^{22}$ What is Intellectual Property. Available at: https://www.wipo.int/edocs/pubdocs/en/ intproperty/450/wipo_pub_450.pdf (accessed: 01.06.2020)

${ }^{23}$ Artificial intelligence is being used to generate works in music, journalism and gaming. These may be termed as AI generated works. Available at: https:/www.wipo.int/wipo_magazine/ en/2017/05/article_0003.html\#: :text=Artificial\%20intelligence\%20is\%20already\%20 being,used\%20and\%20reused\%20by\%20anyone (accessed: 01.06.2020)

${ }^{24}$ Lexology AI and copyright authorship: still mind over matter? Available at: https://www. lexology.com/library/detail.aspx?g=404f4311-bcc4-4049-b62e-d521ccca90e1 (accessed: 05.06.2020) 
Hence, the relationship between AI and IP is mutual: IP impacts AI and AI affects IP. Patent and copyright codes are the most relevant systems of protection for AI, mainly when AI can freely generate inventions. There are numerous cases of applications for patent protection where applicant have named an AI application as the inventor. The question that arises in the scenario is whether the law should permit an AI application to be the inventor or should whether it should be obligatory for a human being to be named as the inventor. Should the law give suggestions on how to decide the human inventor or let the stakeholders decide through private arrangements? Additionally, the main question is who should be documented as the owner of a patent concerning an AI application? Do current legal provisions suffice to consider the specificities of inventions generated by AI, or should explicit legal provisions be introduced? Should the availability of patent protection of autonomously generated inventions by an AI application be excluded by the law?

Additionally, one can raise the question of the explanation of patentability, specifically an inventive step or non-obviousness. In particular, what art does the standard refer to? Finally, the condition of disclosure could be challenging for an invention generated by an AI application. Given that the algorithms of machine learning change over time, how can the condition of disclosure be fulfilled? Must the data used to train an algorithm be revealed or defined in the patent application? Based on the answers to these questions, lawmakers may be led to consider that a sui generis system of IP rights for AI-generated inventions should be developed to adjust innovation incentives for $\mathrm{AI}^{25}$.

The promise of AI does not exist exlusively in either machines or people; instead, it arises from their interplay. AI-generated work and inventions pass the Turing Test, but AI's real test is whether legal architecture built around the foundation of human artistic and advanced endeavours may hinder its evolution. Copyright law and patent law must address this reality head-on [Lim D., 2018: 813].

\section{Who is the owner of an Al-generated invention?}

\section{Al poses 4 challenges to patentability}

The four challenges outlined above are further discussed and elaborated below:

${ }^{25}$ WIPO. Conversation on Intellectual Property and Artificial Intelligence: Draft Issues Paper on Intellectual Property Policy and Artificial Intelligence. WIPO IP/AI/2/GE/20/1, 13 December 2019. Available at : https://www.wipo.int/export/sites/www/about-ip/en/artificial_intelligence/call_ for_comments/pdf/ms_switzerland.pdf (accessed: 05.06.2020) 


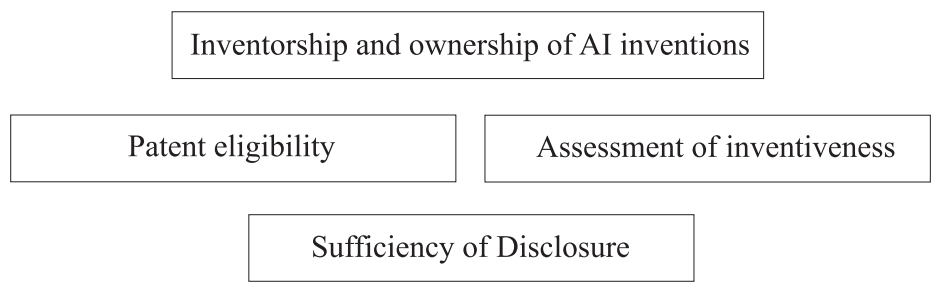

\section{Inventorship and ownership of AI inventions}

An inventor is a person who creates or generate an invention by applying their creative action. It can be proposed that an inventor is a human being or a legal person.

\section{Patent eligibility}

It has been debated whether AI-generated inventions are computer-implemented inventions.

\section{Assessment of inventiveness}

Application of AI may cause an upsurge in skilled people's knowledge, which might be problematic to establish. Skilled people should form an interdisciplinary team that is capable of using AI. A policy question arises here: Can a machine be acknowledged as a skilled person?

Sufficiency of disclosure

It is believed that an invention must be appropriately disclosed in a manner that is clear and complete by a person skilled in the art. In the case of AI, the following problems arise:

Describe how an AI algorithm functions is challenging.

Protecting the method as well its generated output is challenging ${ }^{26}$.

Practically no law exists for the patentability of AI-generated inventions. All jurisdictions require patent applications to reveal an inventor who is a natural person. This prerequisite is intended to protect and recognise the rights of human inventors. However, inventors do not inevitably own their patents; in fact, patents are usually owned by businesses. Ownership rights may be passed on to a legal entity from an individual by means of contractual assignment or otherwise by the benefit of the law. It may be considered as an example that in numerous jurisdictions, ownership is transferred mechanically to an employer if the invention is formed inside the scope of employment. Additionally, even if an inventor does not possess a patent,

${ }^{26}$ Heli Pihlajamaa Director Patent Law, Dir. 5.2.1 Committee on Patent Law, 20 February 2019. Legal aspects of patenting inventions involving artificial intelligence (AI) Summary of feedback by EPC contracting states. 
people are assured of receiving due credit given laws requiring a natural person to be recorded as an inventor. Nevertheless, the above laws were created without accounting for the prospect of creative activity by machines.

\section{Legal personhood of Al}

The legal personhood of artificial intelligence [Solum L., 1991: 1231] can be addressed by considering three relevant background issues [Kurki V., 2019]. These focus on the moral value of AI, i.e., ultimate-value context; on whether AI can or should be held accountable (responsibility context); or on whether AI can obtain a more sovereign role in commercial transactions (commercial context). This paper claims that strong AI, which is as proficient in executing parallel tasks as human beings, can undoubtedly function as legal persons regardless of whether such AI is worthy of moral consideration. If AI can function as a legal person, it can be granted legal personhood on somewhat similar grounds as a human. The majority of this chapter focuses on the role of AI in commercial contexts, and new theoretical tools are proposed that would help distinguish among different legal personhood arrangements for commercial AI.

\section{DABUS Patent Application}

In November 2019, a patent application was filed with the European Patent Office. The applicant claimed the following:

The patent application specified 'DABUS' (which is a type of connectionist $\mathrm{AI})$ to be chosen as 'the inventor'.

The applicant would obtain the right to European Patent for the solitary motive that he is 'the employer' as well as 'the successor in the title'.

\section{European Patent Office (EPO) - Decision on DABUS}

The EPO was rejected the DABUS patent application on the basis of noncompliance with Article 81 and Rule 19 of the European Patent Convention. To be more precise, the office emphasized that the prevailing legal framework of IP is applicable only to legal persons, natural persons, or bodies' equivalent to legal persons. Clearly, 'artificial intelligence' does not fall within any of the categories mentioned above. 
The decision, in brief, rested on the concept of 'legal personhood' and how it is not applicable to 'AI Systems' since it has not been accredited the same by virtue of any legislation or jurisprudence. Furthermore, the judgement also drew that 'AI Systems', having no legal personhood, have no rights; consequently, they cannot have legal title over their output or invention or transfer it or even be employed for the sole reason of absence of rights that flow from legal personhood ${ }^{27}$.

\section{IPR for Al-generated works}

\section{Uncertainties in Al-generated works}

Since AI systems are not natural persons and AI-generated works are regarded as computer-generated under Section 2(d) of the Copyright Act, ambiguity exists regarding the identification of the "person who caused the work to be created». Is it the person who created the AI system or the person who programmed it? Should it be the owners of the AI system or companies and financial stockholders in the AI sector? Or will it be the end-user who uses the AI system to produce a certain output? The lack of accuracy and the particulars involved in defining the author of an AI-generated work make it problematic to determine the 'first owner' of copyright under Section 17 of the Copyright Act.

Under Indian copyright law, in some situations copyright ownership may be approved for non-natural, legal or juristic persons (e.g., companies, organisations or the government). Consequently, if impending AI systems are recognised as legal or juristic persons, they could be granted copyright ownership in some circumstances; however, this would create challenges relating to copyright transferability and the financial and commercial aspects of copyright ownership.

Since AI systems are not considered natural persons (thereby removing the issue of affording AI systems copyright authorship), the lines appear to be distorted concerning the acknowledgement of AI systems as legal persons.

Indian courts have yet to address these intricate matters concerning AIgenerated works and copyright authorship and ownership.

27 Shah S. Dabus Machine: The Harbinger to Debates on Artificial Intelligence as an 'INVENTOR' under patent laws. Available at: http://rsrr.in/2020/02/22/dabus-machine-the-harbinger-to-debateson-artificial-intelligence-as-an-inventor-under-patent-laws/ (accessed: 12.06.2020) 


\section{IPR for Al-generated works under global jurisdiction}

\begin{tabular}{|l|l|}
\hline \multicolumn{1}{|c|}{ Name of the National Jurisdiction } & \multicolumn{1}{c|}{ Comments } \\
\hline $\begin{array}{l}\text { US Patent and Trademark Office } \\
\text { (USPTO) }\end{array}$ & $\begin{array}{l}\text { An AI system cannot be credited as an inventor } \\
\text { in a patent }{ }^{28}\end{array}$ \\
\hline UK Intellectual Property Office (UKIPO) & AI cannot be considered as an inventor ${ }^{29}$ \\
\hline Europe Patent Office (EPO) & An AI entity cannot be an inventor ${ }^{30}$ \\
\hline India & $\begin{array}{l}\text { AI cannot be an inventor according to Section } \\
\text { 3(k) of the Indian Patent Act, mathematical } \\
\text { and business methods, computer programs } \\
\text { or algorithms are defined as non-patentable }\end{array}$ \\
\hline
\end{tabular}

\section{Copyright law and Al-generated works}

AI-generated works and copyright law have been discussed quite frequently. In 1988, the United Kingdom became the first country to offer explicit copyright protection for AI or «computer-generated» works. When a copyrightable work is created, but no natural persons are found to be suitable as authors, the "producer» of the work is considered to be the author.

On the other hand, the United States Copyright Office (USCO) has adopted the reverse approach. Since 1973 the office has practically applied a «human authorship policy ${ }^{32} »$ [Ginsburg J., 2018: 131-135].

The human authorship policy was seen with the «Monkey selfies» case Naruto v.Slater ${ }^{33}$. This case concerned a sequence of images clicked by an Indonesian crested macaque named Naruto. People for the Ethical Treatment of Animals (PETA) litigated on Naruto's behalf, using the argument

${ }^{28}$ Porter J. The Verge,: US patent office rules that artificial intelligence cannot be a legal inventor. Available at: https://www.theverge.com/2020/4/29/21241251/artificial-intelligenceinventor-united-states-patent-trademark-office-intellectual-property (accessed: 12.06.2020)

${ }^{29}$ McKenna C. Lexology: UK Intellectual Property Office finds that patent law does not cater for inventions created by AI machines and calls for debate inventor. Available at: https://www.lexology. com/library/detail.aspx?g=ad32b072-23d3-4db4-95f5-bb71c0826dc5 (accessed: 10.06.2020)

${ }^{30}$ Olvi G., Massalongo S. Mondaq. Italy: Artificial Intelligence: What kind of IP Protection. Available at: https://www.mondaq.com/italy/trade-secrets/767332/artificial-intelligence-whatkind-of-ip-protection?login=true (accessed: 01.06.2020)

${ }^{31}$ Lazaro L. Mondaq. India: Artificial Intelligence in the world of IP. Available at: https://www. mondaq.com/india/patent/892134/artificial-intelligence-in-the-world-of-ip (accessed: 10.06.2020)

32 This policy forbids copyright protection in case the works are not generated by a human author.

${ }^{33}$ Naruto v. Slater, No. 16-15469 (9th Cir. 2018). 
that he should possess the copyright to the photographs. But the case was terminated, as the United States Congress did not authorise animals to file suit under the Copyright Act. As a consequence, the advantages of the human authorship prerequisite have never been tested in court.

\section{Patent protection for Al-generated works}

Patent protection should be obtainable for AI-generated works because it will encourage innovation. The vision of holding a patent will not unswervingly motivate AI, but it will incentivise some of the people who develop, own, and use AI. Permitting patents for AI-generated works, consequently, will promote the growth of inventive AI, which will eventually lead to more innovation for society.

Patents can encourage disclosure of information and the commercialisation of socially valuable products. Patents for AI-generated works will achieve these targets as well as any other patents. On the other hand, not permitting protection for inventions generated by AI would lead to businesses not being able to deploy AI to invent. The inability to submit a filing based on an AI-generated invention would cause situational gamesmanship with patent offices.

Apart from providing fortification for AI-generated inventions, AI should be listed as an inventor when it is inventing, as this would shield the rights of human inventors. Listing a person as an inventor of an AI-generated invention would cause no harm to AI, which ultimately is not interested in being recognised. On the contrary, permitting people to own credit for work they have not done would undervalue human inventorship ${ }^{34}$. It would put the work of a person who simply asks AI to resolve a problem on an equal foothold with someone who is lawfully and justifiably inventing something new. AI can definitely not own a patent. AI systems have a dearth of both moral and legal rights; hence, they do not possess the ability to own property. There would be no advantages or benefits, but substantial costs in order to allow AI to have ownership. Again, citing an AI as an inventor does not mean providing rights to machines, but it would lead to protection of the moral rights of traditional human inventors and the verac-

${ }^{34}$ Inventorship is an important concept in patent law. Inventors are those who contribute the ingenuity necessary to create an invention. Quinn G. Inventorship 101: Who are Inventors and Joint Inventors? Available at: https://www.ipwatchdog.com/2018/03/09/inventorship-joint-inventors-coinventors/id=94592/ (accessed: 10.06.2020) 
ity of the patent system. It is often the case that the inventor of a patent is not its owner ${ }^{35}$ [Feldman R., Thieme N., 2019]; [Firth-Butterfield K., Chae Y., 2019].

Technology has a propensity to advance more rapidly than the law. As AI-based technologies and machine learning continue to be considered other industrial areas, the need for legal supervision on this subject will increase exponentially ${ }^{36}$ [Fenwick M. et al, 2016]. The prime area of legal study that is disposed to the range of legal intricacies associated with this technology is the field of intellectual property (IP). While much has been discussed about the effects of computer-authored work in copyright law, less discussion has taken place regarding how analogous technologies will dislocate patent law [McLaughlin M., 2018]. «As developers gain the ability to create machine learning technologies capable of independently generating inventions, experts must examine the legal scope of inventorship by looking toward the text of the constitution, judicial decisions, legislative actions, and the philosophical reasoning behind such jurisprudence.» [Fisher W., 2001].

Today, machine learning can be used for computer-generated patent claims; this computer-generated content has a wide variety of latent applications that could bring chaos to the patent legal system [Plotkin R., 2009]. There have been no known instances of an independently computer-generated invention. These expansions raise the following question: If machines can compose patentable subject matter entirely independent of human intervention, should they be granted property rights and under what circumstances should these rights be granted?

A vital understanding of inventorship will be assessed as society looks toward the predictable depths of the «artificial invention age» in order to determine whether inventions that are computer-assisted or computergenerated and made with the aid of AI should result in patents. To evaluate this subject, two issues must be considered. First, a range for analysing the degree of human intervention that occurs throughout a given inventive process will be established. Machine learning could be an enormously useful instrument to assist inventors. In addition, it would enable computers

35 Abott R. The Artificial Inventor Project. Available at : https://www.wipo.int/wipo_magazine/ en/2019/06/article_0002.html\#: :text=People\%20have\%20claimed\%20to\%20have,in $\% 20$ such $\% 20$ a\%20patent $\% 20$ application.\&text $=$ However\%2C\%20these $\% 20$ laws $\% 20$ were $\% 20$ created,of $\% 20$ inventive\%20activity\%20by\%20machines (accessed: 10.06.2020)

${ }^{36}$ Heath N. What is AI? Everything you need to know about Artificial Intelligence. Available at: https://www.zdnet.com/article/what-is-ai-everything-you-need-to-know-about-artificialintelligence/ (accessed: 05.06.2020) 
to make inventions without any human intervention or influence. Computer-assisted and computer-generated inventions could also be examined through a philosophical lens to determine the point along the spectrum at which human intervention is so minimal that the right to a patent is relinquished.

«The time has arrived for our federal courts and legislature to begin more carefully considering how computer-generated inventions should be treated in the patent ecosystem» [Hattenbach B., Glucoft J., 2015: 19, 32].

\section{Can the Copyright Act handle the future of Al systems?}

As AI systems develop competences conventionally attributed to humans, such as creativity and autonomy, predetermined notions about human intelligence and creations of the mind are defied, which in turn puts pressure on prevailing legal frameworks to grow.

With the decrease in human intervention in AI systems and AI-generated works, policymakers worldwide may ultimately have to create systems and codes that consider the moral, commercial and accountability aspects of copyright protection in AI-generated works as well. It would be interesting to see how the law evolves to protect and encourage AI developers and users on the one hand and AI systems and their potential juristic personality on the other.

One of the prime objectives of this research paper is to determine the impact of International and National laws and treaties on IP rights for AI-generated solutions for the pandemic

"WIPO is an agency of the United Nations that represents the global forum for IP services, policy, information and cooperation for its Member States.» WIPO champions the expansion of a balanced and effective international IP system that allows innovation and creativity for the benefit of all. The scope of this mandate is the objective of promoting invention and creativity for the economic, social and cultural development of all countries; the Member States have requested that WIPO provide a forum leading the discussion on AI and IP policy.

The ongoing WIPO conversation on AI policy is the first step in this process.

A distinction must be made between human-created works or inventions and machine-created works or inventions. The works and inventions created by humans are protected by the prevailing IP frameworks, which 
include patents, copyright, industrial designs, and trade secrets. The debatable question is whether these existing frameworks and systems need to be altered for works and inventions by machines. In broad terms, the deliberations regarding machine-made inventions or works focus on:

Possible protection for the actual machine created work/invention itself. This leads to an emphasis on the question of whether AI can be an inventor or creator within the current IP frameworks.

Possible protection of AI algorithms and software.

Possible rights regarding the primary training data and data inputs.

There is also a debate concerning the line between human-made and machine creation, i.e., what amount of human input or supervision may be required to fall within one or the other. The WIPO Technology Trends $2019^{37}$ report on artificial intelligence offers data and analysis that classify key trends, crucial players and the geographical spread of AI-related patents and scientific publications.

\section{Policy recommendations and alternative mechanisms}

\section{Patent pooling}

«A patent pool is well-defined agreement between two or more patent owners to license their patents to one another or to third parties.» Patent pools mostly come into view when some inventor gets trapped in a multifaceted technology that needs a complementary patent to achieve efficacy; however, the complementary patent belongs to another patent holder.

Patent pools are may be termed as private arrangements that allow participants to function under each other's' patent rights in order to manage and control the pooled rights on a central basis, as well as to grant licenses of the pooled patents to third parties, with the profits split amid the pool members according to a settled formula. Patent pools have existed for more than a century in various industries ranging from oil refining, to aircraft to semiconductors and even digital media. In all of these cases, pools have allowed the efficient alliance of patents in a manner that has eased licensing and commercialisation.

${ }^{37}$ WIPO Conversation on Intellectual Property and Artificial Intelligence. Draft Isues Paper on Intellectual Property Policy and Artificial Intelligence, prepared by WIPO Secretariat. Available at: https://www.wipo.int/meetings/en/details.jsp?meeting_id=51767 (accessed: 10.06.2020) 
Patent pools have also been recommended as instruments to address severe public health emergencies such as disease outbreaks and pandemics. Patent pooling structures were vigorously deliberated and considered in the SARS outbreak in 2002-2003, the H5N1 influenza outbreak in 2005, and the H1N1 influenza pandemic of 2009. However, regardless of the apparent need for aggregation of distributed patent rights in order to battle these diseases, patent pools were never formed. The reason that patent pools may not have effectively formed in these areas may be associated with antitrust law. A patent pool essentially comprises a variety of patents held by diverse owners. But when a pool aggregates rights including technologies that may be substituted for one another, for example, patents covering various types of vaccines, innovation could be abridged (i.e., why attempt to develop an enhanced vaccine when all vaccines are licensed under the pool?). When pooled patents are complementary (e.g., many patents casing aspects of the equivalent vaccine), pools are regarded as enhancing proficiency and innovation. For this reason, most antitrust enforcement agencies harmonise over the fact that the patents included in a pool should mostly be complementary and not substitutes for each another.

In 2010, the Unitaid initiative of the United Nations World Health Organization (WHO) formed the Medicines Patent Pool (MPP). The mission of MPP is to cumulate patents, clinical trial data and additional IP relating to HIV/AIDS, Tuberculosis and Hepatitis- $\mathrm{C}$ medications. It also aims to make all these available at minimal or no cost to manufacturers that promise to produce and offer drugs at wholesale prices to users in low-income countries $^{38,39}$.

MPP acts as a clearinghouse or intermediary that obtains inbound licenses from prepared IP holders and then leases those rights to generic drug manufacturers operating in developing nations. These licenses can be royalty-bearing or royalty-free, are available on an $a$-la-carte basis, and do not essentially combine the rights licensed to MPP (which avoids some of the antitrust issues).

Advocates have proposed that an MPP-like patent pool be formed to fight the Covid-19 pandemic. The President and Health Minister of Costa

${ }^{38}$ Patent Pooling: A boon amidst COVID-19 Pandemic. Available at: https://www.lexology. com/library/detail.aspx?g=ba09f470-2269-4ae3-92c0-c52f769633ac (accessed: 10.06.2020)

39 OECD. Why Open Science is critical to combatting Covid-19. Available at: http://www.oecd. org/coronavirus/policy-responses/why-open-science-is-critical-to-combatting-covid-19-cd6ab2f9/ (accessed: 10.06.2020) 
Rica requested that the WHO «undertake an effort to pool rights to technologies that are useful for the detection, prevention, control and treatment of COVID-19.» According to the application, the projected pool «should include existing and future rights to patented inventions and designs, as well rights to regulatory test data, know-how, cell lines, copyrights and blueprints for manufacturing diagnostic tests, devices, drugs, or vaccines. It should provide for free access or licensing on reasonable and affordable terms, in every member country.»

An IP pool administered by a United Nations agency, especially if it is truly global in scope, could lessen many patent-related obstacles to the development, production and distribution of vaccines, diagnostics, therapeutics and equipment in the fight against Covid-19. To ensure that such a pooling effort is operative, the WHO must act quickly and conclusively in defining the details of the proposed arrangement and in persuading patent holders in both the public and private sectors to join the effort.

If executed properly, a COVID-19 patent pool could reassure innovation and advance the accessibility of life-saving medications, boost further innovation, as well as restructure and quicken the adoption of diagnostic standards.

Patent pooling can quicken the development of a medicine for COVID-19 while being clear about all the legalities, patent rights and bringing together big pharma companies with generics companies in order to create the required medicine(s) for low- and middle-income countries. It would be a win-win situation, because the patent holders will receive royalties for their innovations, thus upholding their income influx while low- and middle-income countries would gain access to medications at reasonable prices $^{40}$.

\section{Compulsory licenses}

The Bayer vs Natco ${ }^{41}$ case for a compulsory licence (CL) for a drug to treat kidney and liver cancers was among the first CL cases in India. Leena Menghaney of Médecins Sans Frontières' Access Campaign said it in a public statement. This decision affirmed that courts can and should act in the

${ }^{40}$ UNESCO. Open Access to facilitate research and information on COVID-19. Available at: https://en.unesco.org/covid19/communicationinformationresponse/opensolutions (accessed: 10.06.2020)

2013 Indlaw IP AB 20. 
interest of public health in the case of pharmaceutical products.» The primary goal is to strike a balance between patents, patients and profits. Past cases in the emerging economic power of India have raised the challenge of striking a balance between public and private interests where, unexpectedly, the vast mainstream is still not protected by health insurance and where most people have to pay for their own treatment.

\section{Open science and open access technologies}

In the coronavirus (COVID-19) pandemic, open science policies can eliminate obstacles to the free movement of research data and ideas, and thus fast-track the pace of research critical to battling the disease. Although the global sharing of research data and collaboration have reached extraordinary levels, challenges remain. There are trust issues with data, lack of specific standards, co-ordination and interoperability, as well as data quality and interpretation. To reinforce the contribution of open science to the COVID-19 response, policymakers must conform to acceptable data governance models, interoperable standards, sustainable data-sharing agreements involving the public sector, private sector and civil society, incentives for researchers, sustainable infrastructure, human and institutional capabilities and mechanisms for access to data across borders.

There is a need for science communication to be transparent and open, without invading people's privacy. It is imperative to control scientific innovations and support principles of openness and inclusiveness in processes that generate solutions to severe health hazards that are likely to bring substantial adversity to humanity.

Scientific communication, research and data offer key structures for creating novel scientific knowledge. It is imperative to recognize that the creation of new scientific knowledge to handle the urgent risk management rests upon creating an open and level playing field and providing absolute access and allocation of scientific contents, technologies and processes to the entire scientific community from developed and developing countries. Access to verified and peer reviewed data, journal articles and laboratory log books is thus essential to finding a remedy to the ongoing crisis. Proven information and scientific research can also keep the public updated on the situation and dispel fears that may be caused by a lack of awareness or misinformation. 


\section{Discussion and conclusion}

Artificial intelligence technologies, despite having been developed through R\&D and related investments, use both primary and secondary open knowledge sources and public domain knowledge for machine learning and therefore act as a data-centric technology. AI technological applications are but virtual platforms that aggregate knowledge, which constitutes the core of big data. Hence, the data that are studied by AI technologies are not the IP of the AI machine as such but of the human generators of the related knowledge (COVID-19 in this case). They are an algorithmic compilation of mined information from the literature that is published by scientists, research scholars, medical practitioners, survey analysts, pharmaceutical experts, etc. into a dataset of filtered and enhanced knowledge. It is this enhanced dataset that could possibly give the AI domain holders (individual or public institutions) a variety of scientific knowledge domains and deeper insights into COVID-19 virus strains that are intended to ultimately develop a vaccine, which is in the public interest. This is indeed an AI-enabled 'deductive methodology' where complex algorithms from diverse sources of information give rise to effective immunisation against the COVID-19 virus strain. Would it be a mistake to consider AI as a tool of research methodology? If so, the IP owner of the AI algorithm that has been used for this specific 'AI induced work' can claim to be a part of the research but not as an owner of the work as such. The mentioning of the AI research tool is also deemed ethical. The authors of the AI induced work are those who have contributed the algorithms i.e., the original authors are multiple individuals or participating research institutions that have either participated in, hosted or funded the crucial preliminary research and have contributed much important algorithmic data which forms the core of the big data on COVID-19. Therefore, the IP ownership of any resulting primary knowledge that has been induced by AI technologies must trickle down to its contributing individuals and institutions. This is because the AI systems can neither defend the knowledge produced by their algorithms nor can a single human or a private entity claim IP ownership for the aggregation of knowledge for having operated or programmed the AI systems at the backend. Therefore, this gives rise to the collective IP ownership of the knowledge on COVID-19 through 'patent pools' where AI has enabled effectiveness in identifying creators of knowledge and effective knowledge creation in such a short span of time and that in a foolproof and trans- 
parent manner where every contribution is acknowledged for its share of primary data. This can be portrayed as an example of cooperative knowledge sharing that can be channelled for the betterment of the 'commons'. Whether or not the AI technology holders socialise or commercialise this 'enhanced knowledge' post aggregation is a question for ethics and morality. But a critical scenario where a vast number of lives are lost and the global economy is in continuous decline would need a change in perception on the usage of AI-induced knowledge irrespective of IP ownership concerns. The COVID-19 pandemic provides an opportunity for AI-induced works in the advanced areas of bioinformatics and virology wherein a partial automation process (AI induced) in vaccine manufacturing gives rise to a paradigm shift in the field of advanced medical science, which is fuelled by machine-learning with as much practical effectiveness as one can imagine. Combining this aspect with the growing importance and relevance of affordable 'universal healthcare' and public health at the crucial juncture of the COVID-19 pandemic brings us to the theory of utilitarianism wherein maximum benefits are accorded to the maximum number of people. The magnitude of the pandemic requires the unified effort of all stakeholders across the globe in arriving at an ever-lasting vaccine solution of at the shortest possible interval. This must be void of any private interests for commercialisation, giving AI the ability to lead global institutions and governments in terms of inclusivity, accountability and transparency in this regard towards affordable vaccination.

According to the World Intellectual Property Organisation (WIPO) Technology Trends report, which considers AI patents for the world in order to paint an inclusive picture pertaining to growth in the field, almost half of the AI patents were filed after 2013, with the numbers totalling around 170,000.

The report also states how India has developed among the top 10 countries for filing AI patients. According to the report, India ranked eighth in 2015 and says that the country has seen a high rate of annual growth in this respect in the previous years.

To claim IP protection, Indian companies should follow these guidelines:

Define the hardware, for example, sensors, servers and the computer system in addition to AI algorithms in the patent.

Describe the procedure or working method used for developing the AI application.

Refrain from putting the spotlight only on programming codes or algorithms of the AI application. 
The reason why United States Patent and Trademark Office (USPTO) looks to collect public information on AI patents is because varying levels of potential uncertainties in such patent filings exist.

The coronavirus pandemic has been unparalleled in its impact, leaving no lives unaffected since it started in late 2019.

It has affected day-to-day work, school, social gatherings, and travel, and it has produced shockwaves to the world's economy and healthcare systems. It is a once-in-a-lifetime kind of crisis occurring on the global stage.

Difficult questions based on ethical dilemmas are being raised by the same.

For different people, there are different questions.

Healthcare workers need to decide how to allocate scarce resources when treating patients suffering from coronavirus.

Government leaders need to look at the allocation of the coronavirus vaccine once it is developed and becomes available.

Businesses where revenues are falling need to decide their focus group. Should shareholders be their target group even after COVID-19?

Above are a few of the numerous ethical challenges raised by this pandemic, as stated by Wonyong Oh, Lee Professor of Strategy at University of Nevada.

In countries such as Italy, China, the United Kingdom, and Spain, frontline medical staff faced an impasse throughout the COVID-19 crisis: Which patients should be treated first when resources are strained to the limit? Should an attempt be made to save as many patients as possible, or save those with the most crucial and vital need?

From an ethical perspective, if the ethics of outcome (utilitarianism) are applied, the aim is to save the maximum number of lives, so the focus should be on patients who have better chances of healing. In contrast, if the ethics of morality (deontology) are applied, then the patients who are at risk, such as patients in serious conditions, elderly patients must be treated first.

The question remains unanswered. The important message is that it shouldn't just be left to just frontline healthcare workers. Strategies and rules can be suggested in order to ease the moral burden, so that they can better emphasise and pay attention to the treatment. Italy and the UK both offer guidelines for their health care professionals ${ }^{42}$.

${ }^{42}$ Global Health New Wire. Covid-19 and the ethical questions it poses. Available at: https:// globalhealthnewswire.com/policy-law/2020/04/22/covid-19-and-the-ethical-questions-it-poses (accessed: 10.06.2020) 
The other question is when the vaccine is developed and made available, who would have access? The idea is if the vaccine would be first available to more susceptible people or people with high social efficacy like medical professionals? Advancement in vaccine development is vital, but once vaccines are available, the circulation of a vaccine is also an important moral question.

The masks, gloves and diagnostic kits distributed are determined by who pays the maximum amount. Hence, the supply and demand curve would not be able to create a solution to the prevailing distribution problem. If vaccines are also distributed in a similar way, poorer countries will regrettably get the vaccines last.

Richer and developed countries may attempt to stock up on vaccines for the welfare of their own citizens. They would be permitted to take this action since there is no regulatory force that requires countries that develop vaccines to share those vaccines with other countries. This is the prime reason why Bill Gates has recently lately for a global approach to combating COVID-19. He said that the vaccine should be a «lobal public good».

Real-time personal location data to trace and gauge the path of infection has been tried globally, especially in Asian countries like China, Korea, and Hong Kong. IT companies can track location statistics using smartphones to prevent the spread of the virus. However, this raises ethical and legal issues concerning the access to personal information.

If we look at utilitarian ethics, tracking this kind of personal data can be permitted with a belief in «maximum benefits for the greatest number.» It is for keeping society safe from infection by forgoing personal privacy. Recently, it seems that views on tracking personal information in the US. and Europe have begun to change. In several European countries, telecommunication companies have begun to use mobile phone data to fight COVID-19. In the US., Apple and Google are working together to track COVID-19 with Bluetooth. IT companies can help governments reduce the spread of the virus with their technologies. At the same time, tech companies need to balance that with protecting individual privacy, which is a new challenge.

The other main question is whether the pandemic will cause some businesses to reconsider the essential feature of the corporation?

The coronavirus pandemic has been unprecedented in its impact, leaving no aspect of life unaffected following its arrival in late 2019.

From day-to-day impacts on work, school, social gatherings, and travel, to larger shockwaves to the world's economy and healthcare systems, COVID-19 is a once-in-a-lifetime crisis on the global stage. 
With such a large crisis comes even larger, albeit, difficult questions to answer.

How will corporate social responsibility change? This is another question prevailing to the pandemic. In recent years, vaccine development by pharmaceutical companies has decreased intensely. Pharmaceutical companies have also abridged their investment in generating new vaccines. The market for vaccines is minor compared to other drugs, and there is no market once the disease is over. Put simply, it's not a profitable attempt for pharmaceutical companies, which means they have no financial motivation to develop vaccines. How can this problem be addressed? Since market capitalism cannot solve it, and governments need to step in.

Sometimes, authors stated the significance of noting that every time a utilitarian solution to a dilemma is implemented, there will be greater wellbeing or happiness in the world. Characteristically, some people will be better off. There may be legitimate moral reasons to stray from a pure utilitarian approach, for example, in order to guard rights or endorse equality. However, seeing the alternative will help societies recognize and deliberate the necessary cost of these other ethical values ${ }^{43}$.

\section{D目 References}

Cutillo C. et al (2020) Machine intelligence in healthcare - perspectives on trustworthiness, explainability, usability, and transparency. NPJ Digital Medicine, no 1, pp. 1-5.

Feldman R. and Thieme N. (2019) Competition at the dawn of artificial intelligence. In: Competition Law for the Digital Economy. Cheltenham: Edward Elgar, 400 pp.

Fenwick M., Kaal W., Vermeulen E. (2016) Regulation tomorrow: what happens when technology is faster than the law. American University Business Law Review, no 6, p. 561.

Firth-Butterfield K. and Chae Y. (2018) Artificial Intelligence Collides with Patent Law. World Economic Forum. Available at: http://www3.weforum.org/docs/ WEF_48540_WP_End_of_Innovation_Protecting_Patent_Law.pdf (accessed: 05.06.2020)

Fisher W. (2001) Theories of Intellectual Property. In: New Essays in the Legal and Political Theory of Property. R. Stephen, ed. Cambridge: University Press, pp. 168-199.

${ }^{43}$ Venkatpuram S. How Coronavirus is shaking the moral universe. Available at: https:// economictimes.indiatimes.com/news/international/world-news/how-coronavirus-is-shaking-upthe-moral-universe/articleshow/74888344.cms?from $=\operatorname{mdr}$ (accessed: 23.06.2020) 
Ginsburg J. (2018) People Not Machines: Authorship and What It Means in the Berne Convention. International Review of Intellectual Property and Competition Law, no 2, pp. 131-135.

Hattenbach B., Glucoft J. (2015) Patents in an era of infinite monkeys and artificial intelligence. Stanford Technology Law Review, vol. 19, p. 32.

Huang C. et al. (2020) Clinical features of patients infected with 2019 novel coronavirus in Wuhan. Lancet, vol. 395, pp. 497-506. DOI: 10.1016/S01406736(20)30183-5.

Hughes J. (1988) The philosophy of intellectual property. Geo. LJ, vol. 77, p. 287.

Kurki V. (2019) The Legal Personhood of Artificial Intelligences. In: A Theory of Legal Personhood. Oxford: OUP, pp. 175-189. DOI:10.1093/oso/9780198844037. 003.0007.

Li L. et al (2020) Artificial intelligence distinguishes COVID-19 from community acquired pneumonia on chest CT. Radiology, p. 200-205.

Lim D. (2018) Al \& IP: Innovation \& Creativity in an Age of Accelerated Change. Akron Law Review, vol. 52, p. 813.

McLaughlin M. (2018) Computer-Generated Inventions. Available at: https:// papers.ssrn.com/sol3/papers.cfm?abstract_id=3097822 (accessed: 23.05.2020)

Plotkin R. (2009) The genie in the machine: how computer-automated inventing is revolutionizing law and business. Stanford: University Press, 2009, 270 pp.

Solum L. (1991) Legal personhood for artificial intelligences. NCL Review, vol. 70, p. 1231.

Wu Y. et al (2020) The outbreak of COVID-19: An overview. Journal of the Chinese Medical Association, issue 3, pp. 217-220. DOI: 10.1097/JCMA. 0000000000000270 